\title{
Simulating Water and Pollution Exports from Soil to Stream during the Thawing Period at the Small River Basin Scale
}

\author{
Pengxiang Wang ${ }^{1}$, Kang Wang ${ }^{1, *}$ and Zuhao Zhou ${ }^{2}$ \\ 1 State Key Laboratory of Water Resources and Hydropower Engineering Science, Wuhan University, \\ Wuhan 430072, China; wangpengxiang@whu.edu.cn \\ 2 State Key Laboratory of Simulation and Regulation of Water Cycle in River Basin, China Institute of Water \\ Resources and Hydropower Research, Beijing 100038, China; zhzh@iwhr.com \\ * Correspondence: wwangkang@whu.edu.cn; Tel./Fax: +027-68776242
}

Citation: Wang, P.; Wang, K.; Zhou, Z. Simulating Water and Pollution Exports from Soil to Stream during the Thawing Period at the Small River Basin Scale. Water 2021, 13, 1506. https://doi.org/10.3390/w13111506

Academic Editor: Francesco De Paola

Received: 17 April 2021

Accepted: 25 May 2021

Published: 27 May 2021

Publisher's Note: MDPI stays neutral with regard to jurisdictional claims in published maps and institutional affiliations.

Copyright: (c) 2021 by the authors. Licensee MDPI, Basel, Switzerland. This article is an open access article distributed under the terms and conditions of the Creative Commons Attribution (CC BY) license (https:// creativecommons.org/licenses/by/ $4.0 /)$.

\begin{abstract}
A physical model was developed to describe the soil-to-stream export processes of water and pollutants in a small river basin during the soil thawing period. The hydrological and pollution transport and transformation behaviors in paddy- and corn-dominated catchments were numerically simulated; the impacts of the pollution concentrations, interactions between the migrated water and pollutants in the soil, and pollutant transformations during the pollution export were coupled. Experimental field data from the Heidingzi river basin during the soil thawing period were used to calibrate the model parameters and evaluate the performance. The mass of the dissolved pollutants from soil particles in the migrated soil pore water was the key factor affecting the pollution export into the streams; the water content directly affected the pollution export. The concentration of the pollutants peaked when the initial exported water was high. The pollutant transport processes influenced the pollution export more significantly after the soil water was significantly reduced. The N-S efficiency coefficients between the simulated and monitored flow rates and the pollution concentrations at the outlets of the paddy- and corn-dominated catchments were $>0.60$ and $>0.54$, respectively. The system deviations between the simulated and monitored flow rates and the pollution concentrations were $<10 \%$ and $<15 \%$, respectively. The proposed model effectively described the water flow, pollution transport and transformation processes.
\end{abstract}

Keywords: frozen soil; pollution exported from oil into stream; pollution transport and transformation; numerical simulation

\section{Introduction}

In seasonal freeze-thaw regions, soil freezing affects the biological processes of microorganisms and the transformation of nitrogen and phosphorus. With the reduction of vegetation and roots, a lot of pollutants accumulate in the soil [1]. Because the soil and snow melt together in spring, the non-point source pollution in the cold regions is cumulative and sudden [2]. However, due to the complexity of the pollutant migration and transformation in the frozen soil thawing process [3], it is difficult to quantitatively analyze the non-point source pollution during this period. Therefore, it is of great significance to simulate the water and pollution export from soil to stream during the thawing period. In unfrozen soil, the transport process of dissolved pollutants can be described using a classic convection-diffusion equation with sink or source terms [4]. However, freezing and thawing affect the migration and transformation of pollutants, primarily in the following three aspects: (1) Freeze-thawing changes the structure of the soil aggregates, which affects the permeability of the soil [5,6]; the contact areas between the soil particles and melted ice thus increases, resulting in more pollutants adhering to the soil particles which dissolved into the river water [7-9]. For instance, in soil aggregates, the opening of the clay lattice will release more fixed ammonia-nitrogen $\left(\mathrm{NH}_{4}{ }^{+}-\mathrm{N}\right)$ [10]. (2) The solubilities of the various ions and the factors that affect solubility are distinctive, which leads to large variations 
in pollutants dissolving from soil into melted ice [11,12]. (3) Freeze-thaw cycles significantly change the population structures and activities of organisms and microorganisms, thereby altering the source and conversion kinetics of pollutants $[13,14]$. Based on this, the migration and transformation processes of pollutants during the soil freezing and thawing periods can be described by adjusting the soil parameters, the source and sink fluxes, and the kinetic parameters of the convection dispersion equation $[15,16]$.

During the thawing period, liquid water is the driving force for the migration of pollutants in soil [17]. The formation of frozen soil changes the water and energy conductivity of the soil, which directly affects the hydrological processes [18,19]. In addition, owing to the impermeability of the frozen layer, the hydrological process during this period is also different from others. Field and laboratory experiments have demonstrated that the proportion of mobile water in the total water, as well as the concentration of pollutants in the mobile water, change constantly during the soil freeze-thaw period [20]. The mechanism of these changes in the pollutant concentration in the thawing soil and its effect on river pollutant concentrations are still uncertain [21]. Pollutants such as nitrogen and phosphorus exhibit complex transformation mechanisms in thawing soil [22,23]. Although it is generally agreed that the low temperatures occurring during freeze-thaw cycles greatly limit the transformation rates of pollutants [24], freeze-thaw cycles accelerate the mineralization of organic nitrogen and the denitrification of nitrates in the soil. They also increase the contents of soluble organic nitrogen and ammonium nitrogen in liquid water [25]. Furthermore, the physical and chemical properties of the dissolved pollutants have been shown to differ significantly in frozen versus unfrozen soil [23]. The solubility of phosphorus increases with an increasing water content. However, the inorganic phosphorus content has been found to increase only slightly after soil thawing, and freeze-thaw cycles have been shown to have no significant effect on inorganic phosphorus in soil [26]. When developing distributed models, the effects the differences in the underlying surface on the migration, transformation, and dissolution of pollutants from soil-to-river should also be considered.

Many studies have accurately monitored $[27,28]$ and simulated [1] the hydrological and pollutant transport processes in the river basin. However, the process of water and pollution export from soil to stream during soil thawing is quite special, and the impact of the frozen soil melting needs to be further studied. The objective of this study was to develop a distributed model to describe the hydrology and pollutant migration and transformation processes in a small river basin during the thawing period, in order to provide theoretical support and an expansion basis for the application of a hydrological and non-point source pollution model in seasonal frozen soil areas. Experimental field data from the Heidingzi river basin, Shuangyang District, Changchun, Jilin Province, obtained during the soil thawing period from 2016 to 2018, were used to calibrate the model parameters and evaluate the model performance.

\section{Materials and Methods}

\subsection{Model Construction}

\subsubsection{Simulation of the Water Flow in Thawing Soil}

The export processes of water and pollutants from the soil into streams during the thawing period are illustrated in Figure 1. The catchment was divided into hydrological units. In each hydrological unit, the melted ice in the soil was modeled to move laterally from soil to stream along a continuous channel formed by the broken soil aggregates above the frozen layer.

The lateral flow flux, $q$, in the soil above the frozen layer at position $x$ was calculated by the following equation:

$$
q=-w K \bar{h}\left(\frac{\partial \bar{h}}{\partial x} \cos i+\sin i\right)
$$


where $\bar{h}$ is the height of the migrating water layer (the distance between the liquid surface and the frozen layer), $K$ is the effective hydraulic conductivity of the soil (i.e., the conductivity of the continuous channel formed by the broken soil aggregates during the thawing process), $i$ is the topographic slope, and $w$ is the width of the flow surface at position $x$. Equation (2) was used to describe the change in the width along the slope:

$$
w=w_{c} x^{w_{b}}
$$

where $w_{c}$ and $w_{b}$ are the parameters used to describe the gradual convergence of the flow along the slope.
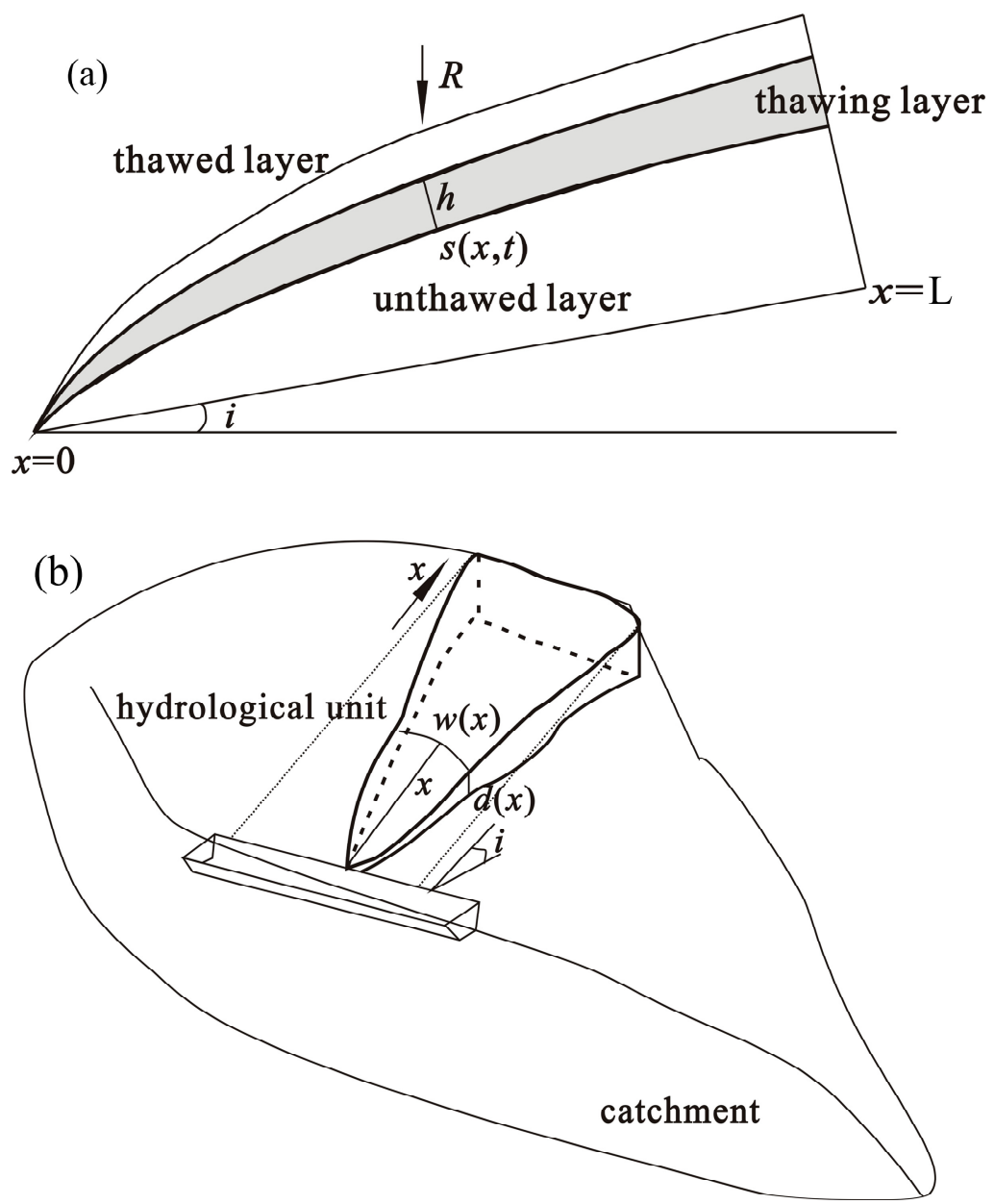

Figure 1. Illustrations of the model used to describe the soil water flow and pollution transport during the thawing period. (a) Generalization of the slope structure; (b) illustration of the model.

Equation (1) was further expressed as:

$$
q=-w K \bar{h}\left(\frac{\partial \bar{h}}{\partial x} \cos i+\sin i\right)=-\frac{K S}{f}\left(\cos i \frac{\partial}{\partial x}\left(\frac{S}{f w}\right)+\sin i\right)
$$

where $f$ is the ratio of the mobile water to the total water. According to the law of the conservation of mass, the change of water storage at position $x$ was calculated as follows:

$$
\frac{\partial S}{\partial t}=-\frac{\partial q}{\partial x}+R w
$$


where $R$ is the source sink term, which is the water discharged into the thawed soil from the upper boundary (i.e., rainfall) in the hydrological unit, and $S$ is the water storage capacity of the hydrological unit. Equation (3) was substituted into Equation (4) to obtain Equation (5):

$$
f \frac{\partial S}{\partial t}=\frac{K \cos i}{f} \frac{\partial}{\partial x}\left(\frac{S}{w}\left(\frac{\partial S}{\partial x}-\frac{S}{w} \frac{\partial w}{\partial x}\right)\right)+K \sin i \frac{\partial S}{\partial x}+f R w
$$

The quadratic term in Equation (5) was then expanded to obtain:

$$
f \frac{\partial S}{\partial t}=\frac{K \cos i}{f w}\left[\left(\frac{\partial S}{\partial x}\right)^{2}+S \frac{\partial^{2} S}{\partial x^{2}}-\frac{3 S}{w} \frac{\partial S}{\partial x} \frac{\partial w}{\partial x}+\frac{2 S^{2}}{w^{2}}\left(\frac{\partial w}{\partial x}\right)^{2}-\frac{S^{2}}{w} \frac{\partial^{2} w}{\partial x^{2}}\right]+K \sin i \frac{\partial S}{\partial x}+f R w
$$

As the changes in $w$ with respect to $x$ are small, $\frac{\partial w}{\partial x}$ was ignored, meaning that Equation (6) was transformed into

$$
\begin{gathered}
f \frac{\partial S}{\partial t}=\frac{K \cos i}{f w}\left[\left(\frac{\partial S}{\partial x}\right)^{2}+S \frac{\partial^{2} S}{\partial x^{2}}\right]+K \sin i \frac{\partial S}{\partial x}+f R w \\
\text { As } \frac{\partial}{\partial x}\left(S \frac{\partial S}{\partial x}\right)=S \frac{\partial^{2} S}{\partial x^{2}}+\left(\frac{\partial S}{\partial x}\right)^{2}, \text { Equation (7) was expressed as: } \\
f \frac{\partial S}{\partial t}=\frac{K \cos i}{f w} \frac{\partial}{\partial x}\left(S \frac{\partial S}{\partial x}\right)+K \sin i \frac{\partial S}{\partial x}+f R w
\end{gathered}
$$

Here, $S$ was linearly approximated as:

$$
S \cong p \bar{S}=p f w D
$$

where $\bar{w}$ and $\bar{S}$ are the average width and water storage capacity of the liquid flow area, respectively; $p$ is between zero and one; and $D$ is the thickness of the soil layer above the frozen layer. Equation (9) was incorporated into Equation (8) to obtain:

$$
f \frac{\partial S}{\partial t}=\frac{K p f w D \cos i}{f w} \frac{\partial^{2} S}{\partial x^{2}}+K \sin i \frac{\partial S}{\partial x}+f R w
$$

The soil water movement equation described by the water storage $S$, was obtained through simplification:

$$
f \frac{\partial S}{\partial t}=K p D \cos i \frac{\partial^{2} S}{\partial x^{2}}+K \sin i \frac{\partial S}{\partial x}+f R w
$$

The upper boundary is the recharge boundary. During the soil thawing period, most of the rainfall infiltrated into the soil, as the rainfall amounted to $<10 \mathrm{~mm}$ in most of the rainfall events and runoff did not occur. The lower boundary is the impervious layer formed by the un-melted ice layer. The water storage capacities at $x=\mathrm{L}$ and $x=0$ are calculated as follows:

$$
\begin{gathered}
K \frac{\partial S}{\partial x}+\frac{K \sin i}{f} S=0 \text { for } x=\mathrm{L} \\
S(0, t)=0 \text { for } x=0
\end{gathered}
$$

\subsubsection{Simulation of the Pollutant Migration and Transformation in Thawing Soil}

During the soil thawing period, melting ice was the main source of movable water in the thawing layers, while the pollutants that adhered to the soil particles dissolved in the water. The concentration of the pollutants in the moving water was affected by the mass of the dissolved pollutants, the liquid water content and the soil flow rate. In order to grasp the mechanism of the pollutant migration and the interactions between the soil and liquid water, the migration and transformation processes from the soil into streams during the thawing period were described using three methods independently. 


\section{(1) Method 1}

In the thawed soil, the pollutant concentration in the moving water was mainly affected by the pollutant mass which dissolved in to the moving water. The pollutant concentration in the thawed soil was expressed as follows:

$$
\frac{\partial S c_{c}}{\partial t}=\frac{\partial}{\partial x}\left(D_{s}(S) \frac{\partial S c_{c}}{\partial x}\right)-\frac{\partial q c_{c}}{\partial x}+S k_{m} c_{m}{ }^{\alpha}
$$

where $c_{c}$ and $c_{m}$ are the pollutant concentrations in the mobile water and soil, respectively, and $D_{s}(S)$ is the hydrodynamic dispersion coefficient of the pollutants. Because pollutants mainly move in free liquid water, $D_{S}(S)$ was given a fixed value. $q$ is the soil liquid water flux, which was calculated using Equation (3), and $K_{m}$ and $\alpha$ are the parameters characterizing the movement of pollutants from soil to mobile water.

(2) Method 2

The processes whereby the pollution adhering to soil particles dissolved in water and the transformation process in liquid water were described using lumped first-order kinetic equations. These two processes formed the source/sink term in the solute transport equation:

$$
\frac{\partial S c_{c}}{\partial t}=\frac{\partial}{\partial x}\left(D_{s} \frac{\partial S c_{c}}{\partial x}\right)-\frac{\partial q c_{c}}{\partial x}+S k_{a c} c_{m}-k_{d e} c_{c}
$$

where $k_{a c}=10^{-\Omega S} k_{m s}$ is the kinetic parameter modified by $S$ and $\Omega$, and $\Omega$ characterizes the bending degree of the soil. $k_{d e}$ is the first-order kinetic coefficient; it characterizes the changes in the pollutant concentrations in moving water.

(3) Method 3

The pollutant dissolving process from soil particles to water was described as follows:

$$
\frac{\partial c_{s}}{\partial t}=\frac{k_{s k} c_{m}^{\beta_{k}}}{1+\eta_{k} c_{m}^{\beta_{k}}}
$$

The pollutant transport and transformation processes were simulated by:

$$
\frac{\partial S c_{c}}{\partial t}=\frac{\partial}{\partial x}\left(D_{s} \frac{\partial S c_{c}}{\partial x}\right)-\frac{\partial q c_{c}}{\partial x}+\frac{\partial c_{s}}{\partial t}-k_{g e} c_{c}
$$

where $\beta_{k}, \eta_{\mathrm{k}}$, and $k_{s k}$ are the kinetic coefficients.

2.1.3. Simulation of the Hydrology, Migration and Transformation Processes of Pollutants in Streams

The water flow at the outlet of the catchments originates from exported water in soil.

The Manning formula was used to simulate the flow rate:

$$
\begin{aligned}
& Q=A C \sqrt{R i} \\
& C=\frac{1}{n} R^{1 / 6}
\end{aligned}
$$

where $A$ is the area of the flow section, $C$ is the Chezy coefficient, $R$ is the hydraulic radius, $i$ is the slope of the stream, and $n$ is the roughness of the channel.

The transformation process of the pollutant in the streams was described using the first-order dynamic formula:

$$
C_{(o u t)}=c_{0} \exp \left(-k_{s t} \times l / u\right)
$$

where $C_{(o u t)}$ is the concentration of pollutants at the outlet of the catchment, $c_{0}$ is the pollutant concentration in the water exported from the soil, $k_{s t}$ is the first-order kinetic coefficient of the pollutant transformation in the stream, $l$ is the length of the pollutant 
migration path (half of the length of the stream in the catchment), and $u$ is the flow velocity, which was calculated using Equation (18).

\subsection{Field Experiment}

In order to calibrate and verify the parameters of the model, field experiments were conducted in the Heidingzi river basin of Shuangyang District, Changchun City, Jilin Province, during the soil thawing period from 2016 to 2018 . This basin covers $74.4 \mathrm{~km}^{2}$, with an altitude range of $114-233 \mathrm{~m}$. Paddy and corn fields account for $14.5 \%$ and $67.2 \%$ of the total river basin area, respectively, while forests account for $11.2 \%$. The basic information of the experimental catchments is shown in Table 1 and Figure 2. The monitoring data show that the groundwater level was lower than the bottom of the river during the freeze-thaw periods. During the thawing period, the water and pollutants in the river were all exported from the soil, and the rural domestic pollutants in the catchment were mainly discharged into farmland, rather than being directly discharged into the river. The maximum frozen soil depth in the experimental area was $158 \mathrm{~cm}$ and the minimum temperature during the freezing period (January) was $-38.4^{\circ} \mathrm{C}$.

Table 1. Basic information of the Heidingzi river basin.

\begin{tabular}{|c|c|c|c|c|}
\hline \multicolumn{2}{|c|}{ Experimental Catchment } & Paddy & Corn & Basin \\
\hline \multicolumn{2}{|c|}{ Area $\left(\mathrm{km}^{2}\right)$} & 10.8 & 49.9 & 74.2 \\
\hline \multicolumn{2}{|c|}{ Average slope $\left(\mathrm{m} \mathrm{m}^{-1}\right)$} & 0.025 & 0.103 & 0.034 \\
\hline \multicolumn{2}{|c|}{ Channel density $\left(\mathrm{km} \mathrm{km}^{-2}\right)$} & $5.361^{\mathrm{a}}$ & 8.81 & 6.04 \\
\hline \multirow{5}{*}{$\begin{array}{l}\text { Soil physical and } \\
\text { hydrodynamic } \\
\text { parameters }\end{array}$} & Clay $(\%)$ & $20.56 \pm 5.67$ & $16.74 \pm 5.26$ & $16.24 \pm 5.80$ \\
\hline & Silt (\%) & $36.78 \pm 12.04$ & $33.11 \pm 11.14$ & $37.00 \pm 10.14$ \\
\hline & Sand $(\%)$ & $41.16 \pm 14.55$ & $48.09 \pm 14.88$ & $44.26 \pm 15.10$ \\
\hline & $\begin{array}{l}\text { Hydraulic conductivity } \\
\qquad\left(10^{-6} \mathrm{~m} \mathrm{~s}^{-1}\right)\end{array}$ & $3.44 \pm 3.31$ & $5.66 \pm 5.85$ & $6.38 \pm 6.57$ \\
\hline & Bulk density $\left(\mathrm{g} \mathrm{cm}^{-3}\right)$ & $1.44 \pm 0.21$ & $1.40 \pm 0.27$ & $1.39 \pm 0.11$ \\
\hline
\end{tabular}

a Total length of the drainage channel in the paddy field/paddy area.

The field experiments were conducted during the thawing periods of the frozen soil (i.e., from after the snow had completely melted until the paddy fields started to flood) in 2016, 2017 and 2018. Monitoring sections were set up at the outlets of three catchments dominated by corn fields, one catchment dominated by paddy fields, and at the outlet of the basin (Figure 2). A Doppler flow meter was used to measure the flow rates. Water samples were taken at these five locations every day during the soil thawing period.

During the thawing period, soil sampling was conducted every 5-7 days. Six locations were selected in each of the above five areas. At each location, soil samples were taken from 0 to $160 \mathrm{~cm}$ depth at $10 \mathrm{~cm}$ intervals. The frost front depths were estimated based on the soil rigidity. After measuring the water content, the soil samples were air dried, mixed with distilled water at a ratio of 1:5, and shaken for $6 \mathrm{~h}$. The filtered solutions and water samples taken from the streams were used to measure the $\mathrm{NH}_{4}{ }^{+}-\mathrm{N}$, nitrate-nitrogen $\left(\mathrm{NO}_{3}-\mathrm{N}\right)$, and soluble phosphorus (SP) concentrations using an automatic chemical analyzer (Cleverchem 200, DeChem-Tech Company, Hamburg City, German). 


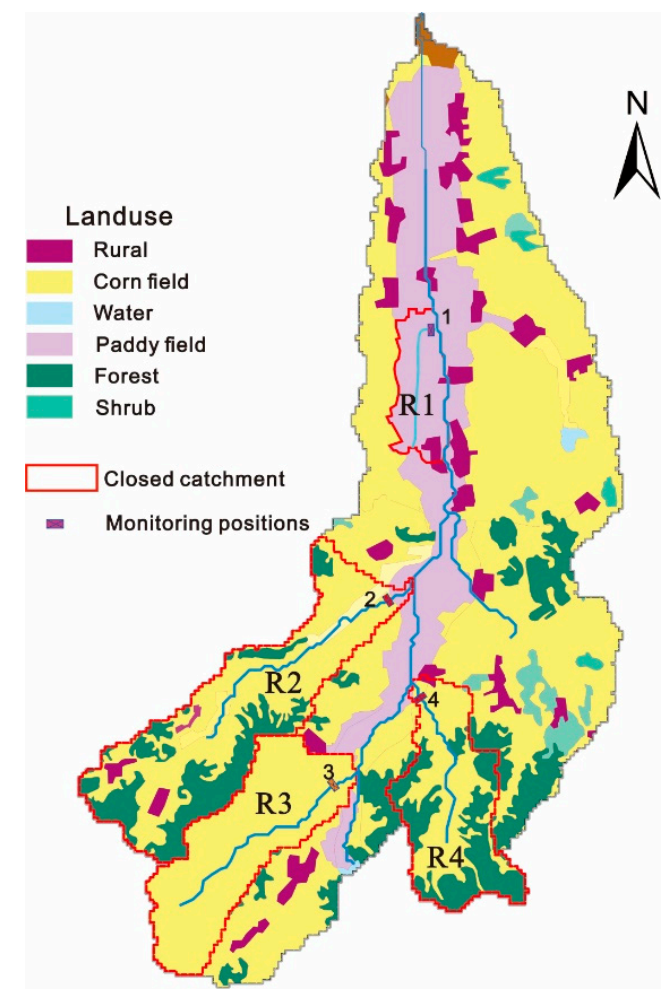

Figure 2. Land use types, streams, and observation sites in the catchments.

\subsection{Parameter Calibration and Model Evaluation}

The model mainly simulated the processes by which water and pollutants were exported from soil into streams. The measured values of the soil pollution concentrations, frost front depths and rainfall during the thawing process were used as the input data. The atmospheric temperature and rainfall during the thawing period of the frozen soil in 2016, 2017 and 2018 are shown in Figure 3.

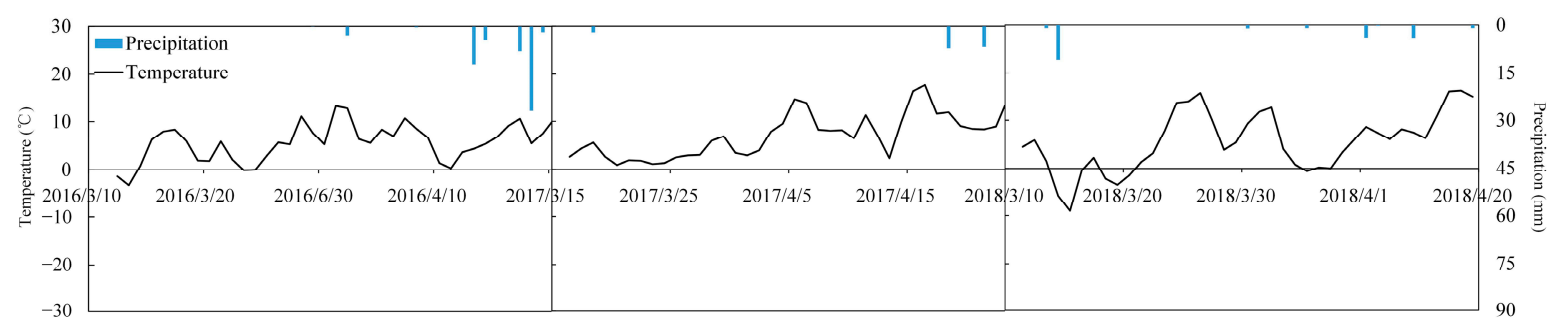

Figure 3. Temperature and precipitation during the thawing period of frozen soil.

The model parameters were determined using the following objective function:

$$
\Phi(b)=\sum_{j=1}^{m_{q}} v_{j} \sum_{i=1}^{n_{q j}}\left(O_{j}\left(x, t_{i}\right)-P_{j}(x, t, b)\right)^{2}
$$

in which:

$$
v_{j}=\frac{1}{n_{j} \sigma_{j}}
$$

where $m_{q}$ is the number of monitored variables (i.e., the flow, $\mathrm{NH}_{4}{ }^{+}-\mathrm{N}, \mathrm{NO}_{3}-\mathrm{N}$ and SP concentrations at the outlets of the catchments), $n_{q j}$ is the monitoring number of the $j^{\text {th }}$ variable, and $O_{j}\left(x, t_{i}\right)$ is the monitoring value of the $j^{\text {th }}$ variable at monitoring position $x$, time $t_{i} . P_{j}\left(x, t_{i}, b\right)$ is the simulation result with the parameter matrix $b$, and $v_{j}$ is the weight 
of variable $J$, which was used to reduce the influence of the magnitude and number of different monitored variables on the objective function.

The Nash Sutcliffe coefficient, $N$; the relative total error, $F_{B}$; and the information entropy, $E$, were used to evaluate the model performance. $N$ was used to evaluate the goodness-of-fit of the model:

$$
N=1-\frac{\sum_{t=1}^{n}\left(O_{t}-P_{t}\right)^{2}}{\sum_{i=1}^{n}\left(O_{t}-\bar{O}\right)^{2}}
$$

where $O_{t}$ and $P_{t}$ are the observed and simulated values at time $t$, respectively, $\bar{O}$ is the average of the observed values, and $n$ is the number of observations.

$F_{B}$ was used to evaluate the systematic deviation between the simulated and observed values:

$$
F_{B}=\frac{1}{n} \sum_{i=1}^{n} \frac{P_{t}-O_{t}}{\left(P_{t}+O_{t}\right) / 2}
$$

Here, $\bar{\alpha}=\frac{\bar{P}}{\bar{O}}$, where $\bar{P}$ and $\bar{O}$ are the averages of the observed and simulated values, respectively. Equation (24) was expressed as follows:

$$
F_{B}=\frac{\bar{\alpha}-1}{(\bar{\alpha}+1) / 2}
$$

Here, $F_{B}=0$ when $\bar{\alpha}=1$, which indicates that there was no systematic error.

As information entropy can characterize a time series, this was used to evaluate the interactive impacts of the soil hydrological and transport processes on the pollutant concentrations. The entropy was calculated as follows:

$$
E=-\sum_{i=1}^{n} p_{i} \log _{2}\left(p_{i}\right)
$$

where $p_{i}$ is the probability of pollutant concentrations at concentration level $i$. For each pollutant during each soil thawing period, the concentrations in the stream were divided into 20 levels (i.e., $n=20$ ). A larger $E$ indicated a more disposed distribution of concentrations.

\section{Results and Discussion}

\subsection{Evaluation of the Simulation of Soil Flow Processes}

The model parameters were calibrated using the observations taken during the soil thawing periods in 2016 and 2017. The calibrated parameters are shown in Table 2. The flow and transport processes in the soil and streams during the thawing period in 2018 were simulated using the calibrated parameters to evaluate the model performances.

Figure 4 shows a comparison of the simulated and observed flow rates and pollutant concentrations at the outlets of catchments dominated by paddy fields and corn fields during the soil thawing periods in 2016, 2017 and 2018. As shown in Figure 3, the average temperatures during the soil thawing periods in 2016, 2017 and 2018 were 7.5, 7.2 and $7.1{ }^{\circ} \mathrm{C}$, respectively. The temperature during the thawing period in 2016, especially at the beginning, was significantly higher than those in 2017 and 2018. Both the simulated and observed water exports were significantly higher in 2016 than those in 2017 and 2018. Compared with 2016, the amounts of water exported from the soils into streams in 2017 and 2018 were $42.9 \%$ and $35.2 \%$ lower in the paddy-dominated catchment, respectively. Furthermore, the impact of meteorology on the water export from the corn-dominated catchments was significantly higher than that of the paddy-dominated catchment. In the corn-dominated catchments, the water exports in 2017 and 2018 were 50.7\% and 51.8\% lower than in 2016, respectively. 
Table 2. Calibrated parameters.

\begin{tabular}{|c|c|c|c|c|c|}
\hline & & Parameter & & Equation & Calibration Value \\
\hline \multirow{13}{*}{$\begin{array}{l}\text { Land surface } \\
\text { Hydrology process }\end{array}$} & \multirow{6}{*}{ Hydrology } & $\begin{array}{c}\text { Equivalent hydraulic } \\
\text { conductivity }\end{array}$ & K & $(10)$ & $\begin{array}{c}12.4 \times 10^{-4} / \\
4.54 \times 10^{-4} / \mathrm{m} \mathrm{s}^{-1 \mathrm{a}}\end{array}$ \\
\hline & & $\begin{array}{c}\text { Confluence shape } \\
\text { coefficient of frozen soil } \\
\text { thawing layer }\end{array}$ & $w_{c}$ & $(2)$ & $7.28 / 4.48 \mathrm{~m}$ \\
\hline & & & $w_{b}$ & (2) & $0.3374 / 0.2411$ \\
\hline & & & Ds & $(12-14)$ & $1.54 / 12.42 / 0.087 \mathrm{~cm}^{2} / \mathrm{s}^{\mathrm{b}}$ \\
\hline & & $\begin{array}{l}\text { Method } 1 \text { Kinetic } \\
\text { Coefficient }\end{array}$ & $k_{m}$ & $(12)$ & $0.064 / 0.035 / 0.014 \mathrm{~d}^{-1}$ \\
\hline & & $\begin{array}{l}\text { Method } 1 \text { Kinetic } \\
\text { Coefficient }\end{array}$ & $\alpha$ & $(12)$ & $1.32 / 0.87 / 1.77$ \\
\hline & \multirow{7}{*}{$\begin{array}{l}\text { Pollutants transport and } \\
\text { transformation in soils }\end{array}$} & $\begin{array}{l}\text { Method } 2 \text { Kinetic } \\
\text { Coefficient }\end{array}$ & $k_{m s}$ & (13) & $0.072 / 0.032 / 0.009 \mathrm{~d}^{-1}$ \\
\hline & & $\begin{array}{l}\text { Method } 2 \text { Soil bending } \\
\text { coefficient }\end{array}$ & $\Omega$ & (13) & $7.82 / 3.44 / 9.87$ \\
\hline & & $\begin{array}{c}\text { Method } 2 \text { Kinetic } \\
\text { Coefficient }\end{array}$ & $k_{d e}$ & (13) & $0.014 / 0.011 / 0.002 \mathrm{~d}^{-1}$ \\
\hline & & $\begin{array}{c}\text { Method } 3 \text { Kinetic } \\
\text { Coefficient }\end{array}$ & $\beta_{k}$ & $(14)(15)$ & $1.32 / 1.17 / 1.54$ \\
\hline & & $\begin{array}{l}\text { Method } 3 \text { Kinetic } \\
\text { Coefficient }\end{array}$ & $\eta_{\mathrm{k}}$ & $(14)(15)$ & $0.37 / 0.12 / 0.54$ \\
\hline & & $\begin{array}{l}\text { Method } 3 \text { Kinetic } \\
\text { Coefficient }\end{array}$ & $k_{s k}$ & $(14)(15)$ & $0.64 / 0.92 / 0.42$ \\
\hline & & $\begin{array}{c}\text { Method } 3 \text { Kinetic } \\
\text { Coefficient }\end{array}$ & $K_{g e}$ & (14) & $0.038 / 0.024 / 0.011 \mathrm{~d}^{-1}$ \\
\hline River Hydrology process & $\begin{array}{l}\text { Pollutant transport and } \\
\text { transformation in river }\end{array}$ & $\begin{array}{l}\text { First-order kinetic } \\
\text { coefficient of pollutant } \\
\text { degradation coefficient }\end{array}$ & $k_{s t}$ & $(21)$ & $0.032 / 0.004 / 0.007 \mathrm{~d}^{-1}$ \\
\hline
\end{tabular}

${ }^{a}$ The calibration values of paddy and corn fields, respectively. ${ }^{\mathrm{b}}$ The calibration values of the first order kinetic coefficients of $\mathrm{NH}_{4}{ }^{+}-\mathrm{N}$ $\mathrm{NO}_{3}{ }^{-}-\mathrm{N}$ and $\mathrm{SP}$, respectively.

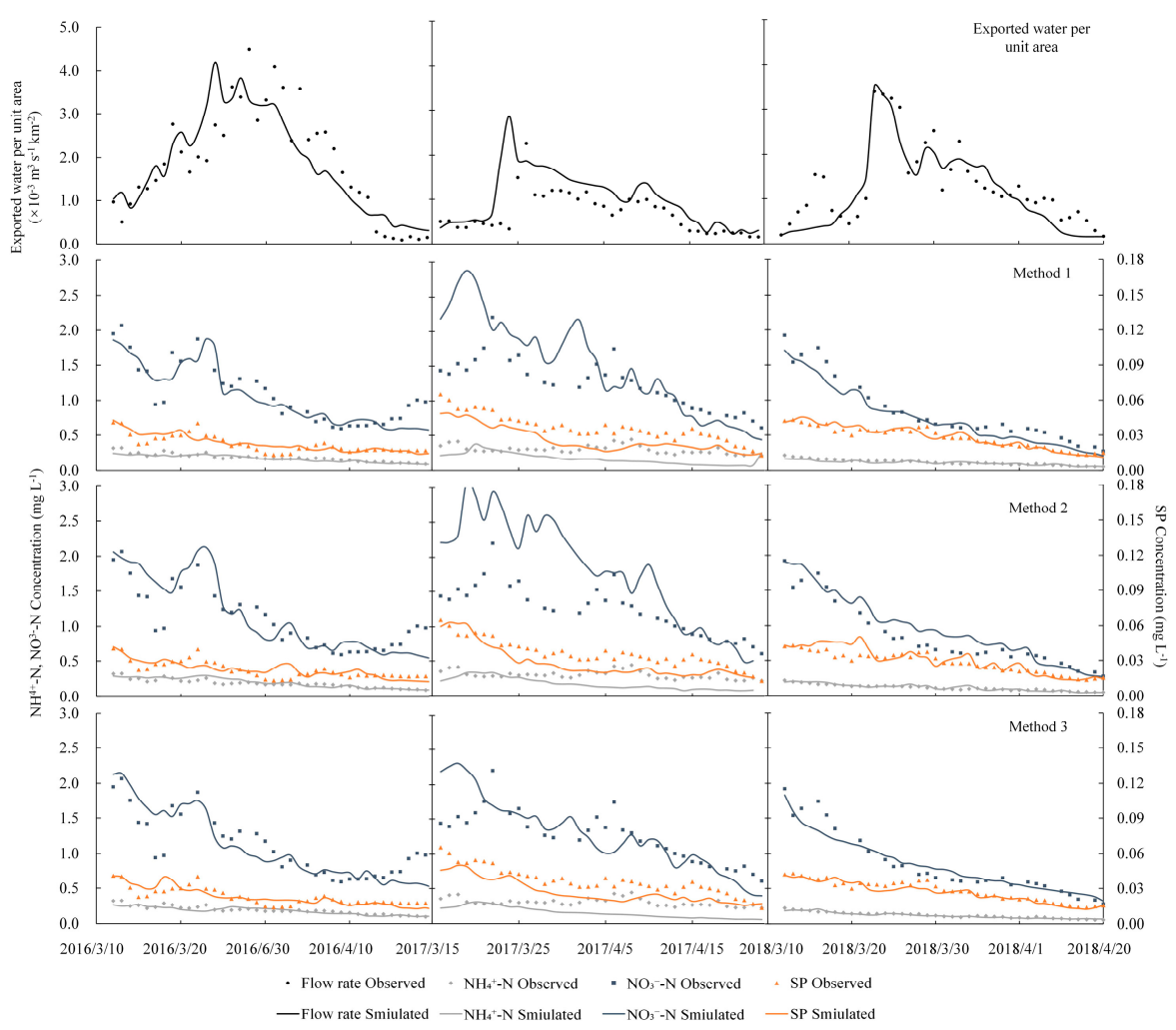

(a)

Figure 4. Conts. 


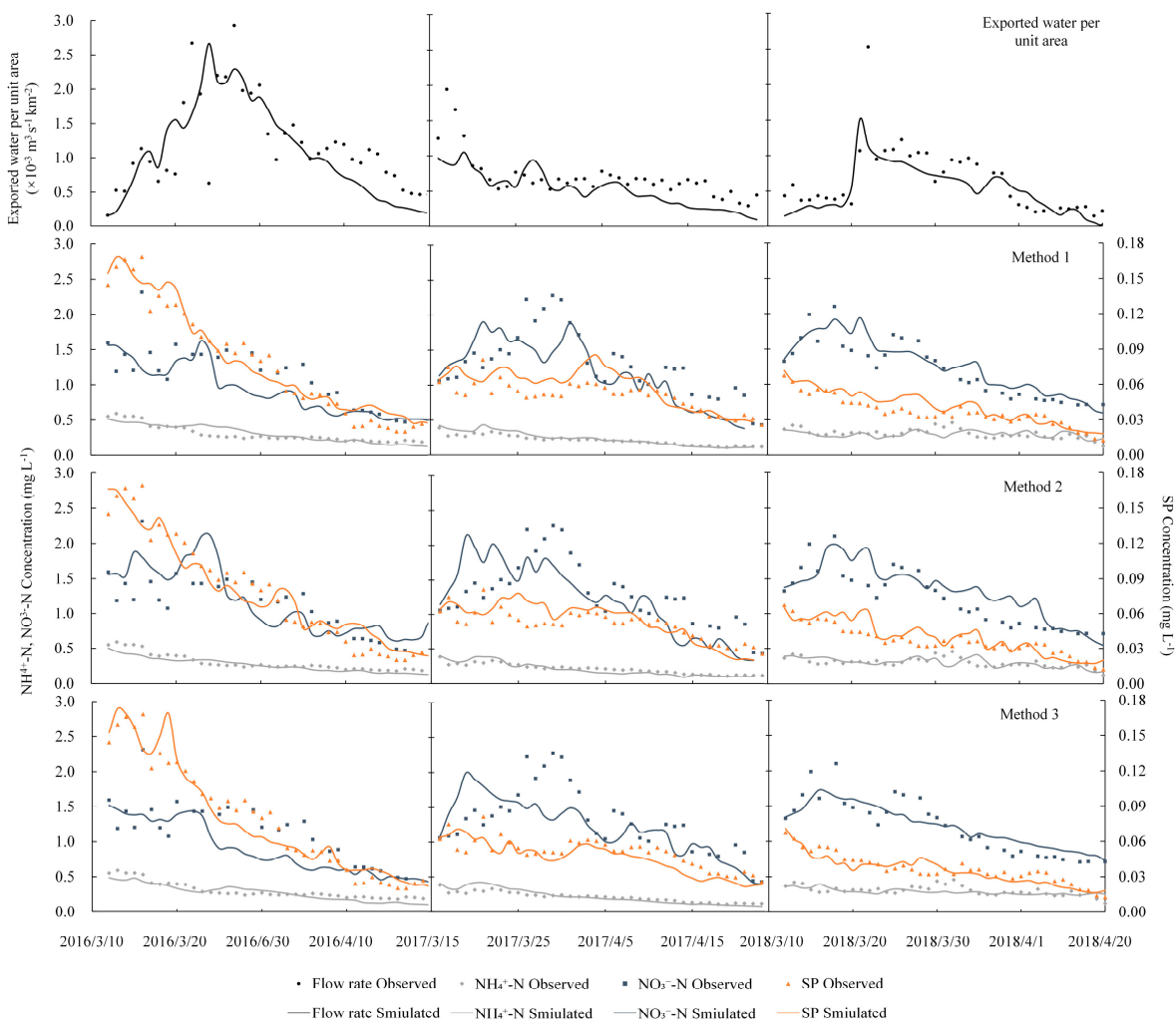

(b)

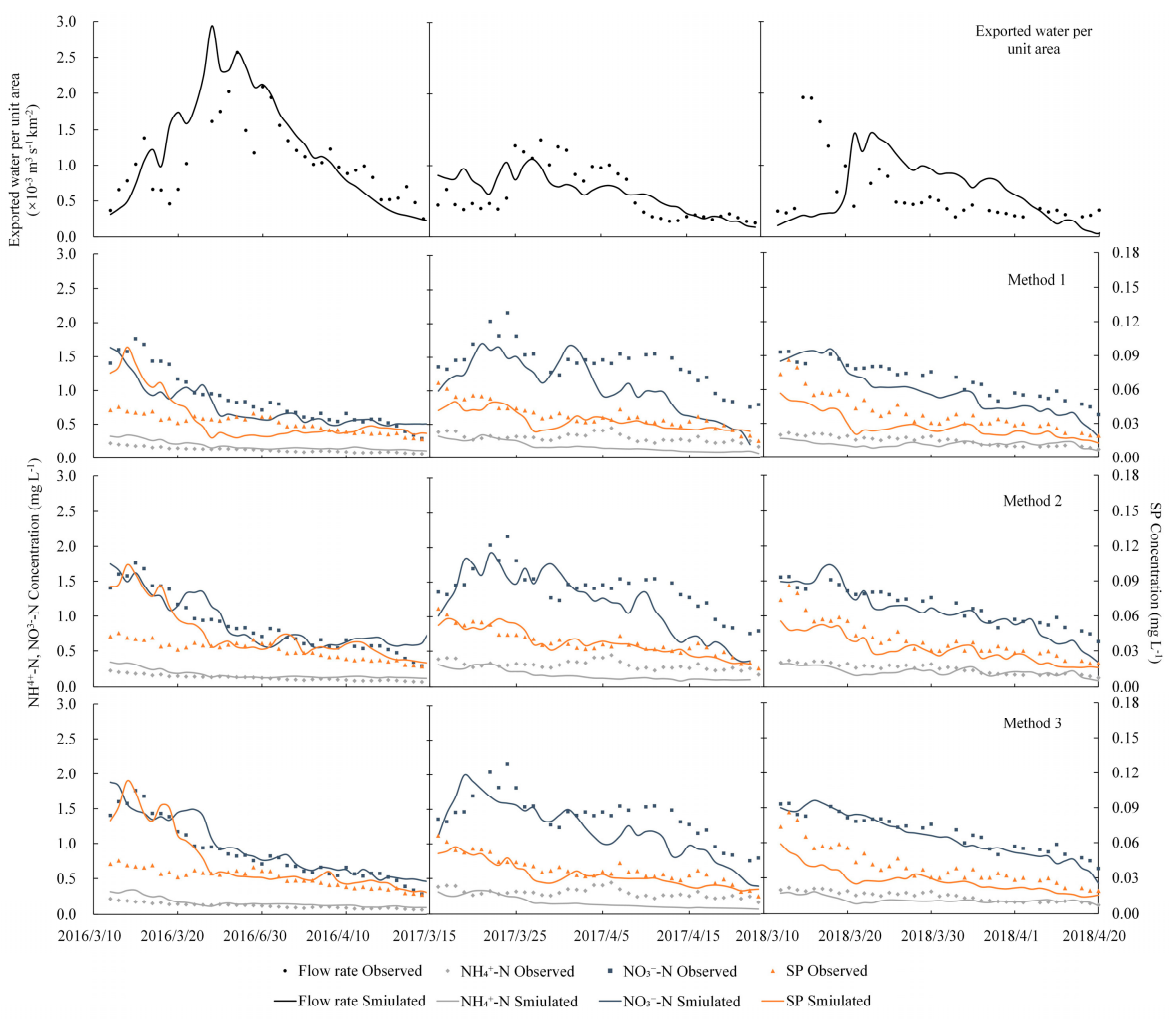

(c)

Figure 4. Measured and simulated values of water and pollutants exported from soil into streams. (a) Paddy-dominated catchments; (b) corn-dominated catchments; (c) small basin. 
As shown in Tables 1 and 2, the calibrated effective hydraulic conductivity, $K$, which describes the permeability of the soil, was $1.64 \times 10^{2}$ times larger than the hydraulic conductivity in unfrozen soil. The freezing and thawing processes affected the water conductivity of the soil by changing the aggregate structure. If the soil flow process was dominated by the soil's hydraulic conductivity, in the paddy-dominated catchment the flow peaked under the saturated conditions. This was inconsistent with the monitored water export process, which indicated that the export of water primarily depended on the amount of melted water. For the corn-dominated catchments, the soil was unsaturated, and the amount of exported water was affected by the initial water storage. The inter-annual variation of the exported water in these areas was more obvious.

The simulation effect of the model was better when there was more exported water. This can be attributed to the fact that the model used changes in the soil water storage to describe the process of soil water moving in the thawed layer from the frozen soil. Therefore, compared with the measured values, the model performed best in both cornand paddy-dominated catchments in 2016. In the same period, the paddy-dominated catchment benefited from a larger volume of exported water, and the simulation effect was better than that of corn, with a smaller relative error. Overall, Equation (11) accurately described the process of the water export during the soil thawing period.

\subsection{Simulation of Pollutant Transport and Transformations in the Paddy-and Corn-Dominated Catchments}

The exported flow per unit area in the corn-dominated catchments was $68.4 \%$ of that in the paddy-dominated catchment. The lower water flux (velocity) allowed water to stay longer in the soil, meaning that more pollutants adhering to the soil particles dissolved in the water. Therefore, the $\mathrm{NH}_{4}{ }^{+}-\mathrm{N}, \mathrm{NO}_{3}-\mathrm{N}$ and SP concentrations at the outlet of the corn-dominated catchment were higher than those of the paddy-dominated catchment by $12.4 \%, 22.8 \%$ and $14.7 \%$, respectively.

For both the paddy- and corn-dominated catchments, the information entropy was smallest for the SP concentrations. The difference in SP entropy between the paddy-and corn-dominated catchments was highest among the three pollutants. The distribution of $\mathrm{SP}$ in the streams was relatively concentrated compared to the other pollutants, whereas $\mathrm{NH}_{4}{ }^{+}-\mathrm{N}$ and $\mathrm{NO}_{3}{ }^{-}-\mathrm{N}$ were more dispersed. This was consistent with the parameter calibration results of the three pollutants (Table 2). The kinetic coefficients (i.e., $k_{m}, k_{m s}$, and $k_{s k}$ in Equations 14-16) used to describe the changes in the SP concentrations in the soil were the smallest among the three pollutants. In the paddy- and corn-dominated catchments, the differences in the information entropy of $\mathrm{NO}_{3}{ }^{-} \mathrm{N}$ and SP were 0.267 and 0.395 , respectively. The differences between $\mathrm{NH}_{4}{ }^{+}-\mathrm{N}$ and SP were 0.524 and 0.467 , respectively. The difference between the information entropy of $\mathrm{NO}_{3}{ }^{-}-\mathrm{N}$ and $\mathrm{SP}$ was smaller than that between $\mathrm{NH}_{4}{ }^{+}-\mathrm{N}$ and SP. The migration abilities of $\mathrm{NO}_{3}{ }^{-}-\mathrm{N}$ and SP have been shown to be notably different [1]. The results presented here also indicate that $\mathrm{NH}_{4}{ }^{+}-\mathrm{N}$ was more affected by the transformation than $\mathrm{NO}_{3}{ }^{-}-\mathrm{N}$ in the mobile water. This interpretation was also consistent with the calibration results of the kinetic parameters shown in Table 2.

Figure 4 shows a comparison of the simulated and observed pollutant concentrations at the outlets of the paddy- and corn-dominated catchments during the soil thawing periods of 2016, 2017, and 2018. For the three simulation methods of pollutants, method 1 only considered the influence of the pollutant concentration in the soil on the pollutant concentration in the mobile water. Compared with methods 2 and 3, the N-S coefficients of the three pollutants in method 1 were $20.3 \%$ and $13.8 \%$ smaller on average, respectively, while the relative deviations increased by $21.1 \%$ and $29.2 \%$ (Table 3). The accuracy of methods 2 and 3 was significantly higher than that of method 1 . The information entropy of method 1 during the calibration period (i.e., the thawing period in 2016 and 2017) and the model evaluation period (i.e., the thawing period in 2018) was relatively close, while those of methods 2 and 3 were significantly different. This indicates that the contact between melting ice and soil particles, and the transformation process of pollutants in mobile water, 
had significant impacts on the pollutants being dissolved into the stream. This finding is consistent with previous research [22].

The pollutants adhered to the soil particles were in full contact with water as the soil pores were fully saturated, and the concentration of the pollutants in the soil had a greater impact on the export process. Method 1 performed better in this period. The contact between migrated water and the pollutants adhered to the soil decreased with the decreasing soil water content. Meanwhile, as the flow rate decreased, the contact time increased. The pollutant concentrations in the mobile water played a key role in the export of pollutants. Methods 2 and 3 considered these factors at this stage and performed well. As discussed above, methods 2 and 3 were more suitable than method 1 in simulating the transport and transformation processes in thawing soil. Method 2 had the highest N-S coefficient, while method 3 had the smallest systematic deviation.

Table 3. Indexes used to evaluate the model performance.

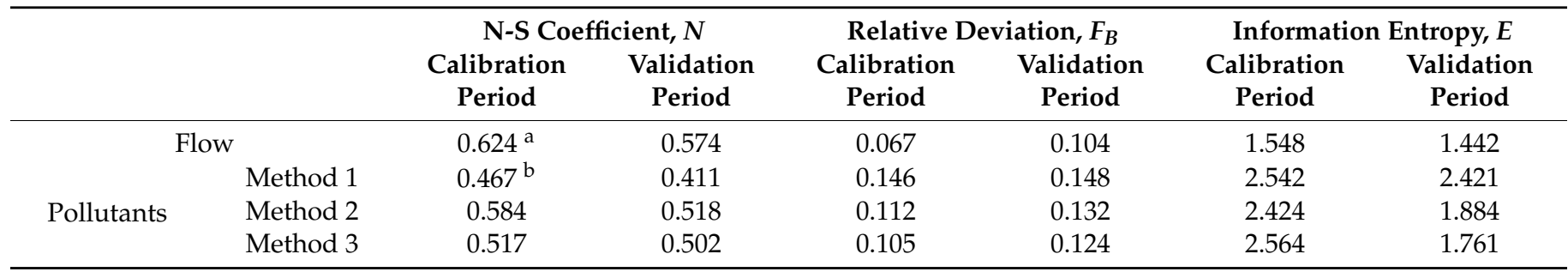

a Average of two underlying surfaces and a small basin. The calibration period comprised the thawing periods of frozen soil in 2016 and 2017, and the verification period was the thawing period of frozen soil in 2018. ${ }^{\mathrm{b}}$ The average value of the three pollutant evaluation indicators.

\subsection{Simulation of Exported Water and Pollutant Transport and Transformation in the Basin}

The exported water per unit area of the basin was close to that of the corn-dominated catchments because of the relatively high proportion of corn in the basin. Table 4 shows that the simulated average value of exported water per unit area in the small basin was closer to the measured value, which was better than the catchments. However, as the river process also involved other hydrological processes such as deep seepage, the fitting effect was not as good as that of the catchments (Figure 4). Therefore, the simulation method needs to be further improved.

Table 4. Comparisons of simulated and monitored flow rates and pollution concentrations.

\begin{tabular}{|c|c|c|c|c|c|}
\hline Experimental Catchment & Pollutants & & Paddy Filed & Corn Filed & Basin \\
\hline \multirow{4}{*}{$\begin{array}{l}\text { Exported water per unit } \\
\text { area }\left(\times 10^{-3} \mathrm{~m}^{3} \mathrm{~s}^{-1} \mathrm{~km}^{-2}\right)\end{array}$} & & Observations & $1.79 / 0.90 / 1.30^{\mathrm{a}}$ & $1.17 / 0.59 / 0.64$ & $1.13 / 0.61 / 0.59$ \\
\hline & & Simulations & $1.78 / 1.02 / 1.15^{\mathrm{b}}$ & $1.07 / 0.53 / 0.52$ & $1.20 / 0.62 / 0.63$ \\
\hline & $\mathrm{NH}_{4}{ }^{+}-\mathrm{N}$ & Observations & $0.180 / 0.211 / 0.117$ & $0.294 / 0.301 / 0.302$ & $0.118 / 0.298 / 0.245$ \\
\hline & & Simulations & $0.176 / 0.176 / 0.120$ & $0.261 / 0.217 / 0.302$ & $0.160 / 0.201 / 0.226$ \\
\hline \multirow{4}{*}{$\begin{array}{c}\text { Concentration at } \\
\text { catchment outlet }\left(\mathrm{mg} \mathrm{L}^{-1}\right)\end{array}$} & $\mathrm{NO}_{3}{ }^{-}-\mathrm{N}$ & Observations & $1.078 / 1.247 / 0.846$ & $1.109 / 1.321 / 1.223$ & $0.841 / 1.395 / 1.142$ \\
\hline & & Simulations & $1.089 / 1.275 / 0.832$ & $0.869 / 1.213 / 1.218$ & 0.987/1.198/1.091 \\
\hline & SP & Observations & $0.023 / 0.037 / 0.028$ & $0.079 / 0.051 / 0.037$ & $0.030 / 0.058 / 0.035$ \\
\hline & & Simulations & $0.022 / 0.029 / 0.026$ & $0.078 / 0.055 / 0.035$ & $0.035 / 0.048 / 0.032$ \\
\hline
\end{tabular}

${ }^{a}$ The average of the monitored values at the outlets of the catchments in 2016, 2017 and 2018, respectively. ${ }^{b}$ The average value of the optimal simulation results.

The concentrations of pollutants at the outlet of the basin were affected by the concentrations of pollutants and the amount of exported water in the two catchments. As is consistent with the paddy- and corn-dominated catchments, method 2 also accurately simulated pollutants at the outlet of the basin. Although the exported water per unit area of the paddy-dominated catchment was greater than that of the corn-dominated catchments, the area of the corn-dominated catchments was 4.62 times larger than the paddy-dominated catchment. Therefore, more water was exported from corn-dominated catchments, such that the concentrations of pollutants at the outlet of the basin should have been closer to the actual values for the corn-dominated catchments. Table 4 shows that the concentrations of 
pollutants in 2017 and 2018 were consistent with this law. However, in 2016, the pollutant concentrations at the outlet of the basin were closer to those in the paddy-dominated catchment where the concentrations were smaller. This may be attributed to the effect of the hydrodynamic characteristics on the reaction's progress, which caused the pollutants to degrade more [29] when the flow rate was high. In addition, compared with the degradation coefficient in summer $\left(0.13-0.26 \mathrm{~d}^{-1}\right)$, as calculated in other studies [30,31], the low temperature in spring likely affected the activities of microorganisms [32], which could explain the smaller $k_{s t}$ obtained in this study.

\subsection{Discussion}

The two main factors affecting non-point source pollution are the flushing and leaching of water (from irrigation or precipitation), and the field fertilization and accumulated nutrients (source and sink items) [33]. During the soil freeze-thaw period, the source was the accumulated pollutants, and the water came from the melting of snow and ice. When simulating pollutants, the amount of water affected the contact time and degree between water and pollutants attached to the soil, thereby affecting the export process of pollutants, which was the dominant factor affecting non-point source pollution. This result is consistent with previous studies [34]. However, ignoring the impermeability of frozen soil would make the simulation of the water export in the thawing phase lower, which would affect the accuracy of the simulation of the pollutants. At the initial thawing stage, the amount of water exported was large and contained no pollutants, and the concentration of the pollutants in the soil had a greater impact on the export process. Method 1 performed better at this stage. The mass of pollutants dissolved from the soil decreased with the decreasing water export. The influences of the pollutant transport processes on the pollution concentration increased. This was attributed to the fact that when the amount of the exported water was small, the frozen soil layer caused the water that should have been supplied to the unsaturated soil or groundwater to be discharged into the river. At this stage, the pollutants in the soil and mobile water had sufficient time to interact, and the concentration of the soil and mobile water was the dominant factor. Methods 2 and 3 performed better than Method 1. Therefore, the impact of the contact between soil pollutants and mobile water, and the migration of pollutants in the water on the simulation of non-point source pollutions during thawing cannot be ignored. In addition, using a higher degree of freedom to describe the migration of pollutants in soil and flowing water can improve the goodness-of-fit between the simulated and measured values to a certain extent, but it increased the system deviation (Method 2).

\section{Conclusions}

During the soil freezing period, roots and vegetation are reduced, and the biological processes of microorganisms are disturbed, causing the accumulation of pollutants in the soil; when the soil is thawing, the pollution is concentratedly exported into the river. This study considered different underlying surfaces and a small river basin as the research objects and constructed a model to simulate the water and pollution export from soil to stream during the thawing period. The field experiment data collected in Shuangyang District, Changchun City, Jilin Province during the soil thawing periods of 2016, 2017 and 2018 were used to calibrate the model's parameters and evaluate its performance. The main conclusions are as follows:

- Numerical simulations of hydrological and pollution transport and transformation behaviors at the small river basin-scale were conducted. The proposed water flow motion equation accurately reflected the flow mechanism of melted ice flowing through channels formed by broken soil aggregates. The constructed model effectively described the pollution export from soil to stream during the thawing period.

- The concentration of the pollutants peaked when the initial amount of exported water was large. The pollutant transport processes influenced the pollution export more significantly after the soil water was significantly reduced. 
- The concentrations of pollutants in the soil, the contact between the soil pollutants and mobile water, and the migration of pollutants in the water all had a significant impact on the export of pollutants. The main controlling factors affecting the pollutions export from soil to stream changed constantly.

It should be pointed out that in order to accurately evaluate the performance of the model, the measured values of the soil pollutant concentrations during the thawing process were used as input data. However, the cumulative amount of each pollutant before the soil begins to thaw was different, and the effects of the soil freezing on the mineralization and denitrification of nitrogen and phosphorus were different. Future studies will simulate the accumulation of pollutants during the freezing process, such that the model can be better coupled with the existing hydrological and pollutant models.

Author Contributions: K.W. and Z.Z. conducted the field experiments, P.W. and K.W. analyzed and processed the data. The programming of the model was carried out by P.W. The writing was performed by P.W., K.W. and Z.Z. All authors have read and agreed to the published version of the manuscript.

Funding: This work was partly supported by grants from the National Natural Science Foundation of China [grant numbers 51679257 and 51879195] and the National Key Research and Development Program of China [grant number 2016YFC0402405].

Conflicts of Interest: The authors declare no conflict of interest.

\section{References}

1. Han, C.-W.; Xu, S.-G.; Liu, J.-W.; Lian, J.-J. Nonpoint-source nitrogen and phosphorus behavior and modeling in cold climate: A review. Water Sci. Technol. 2010, 62, 2277-2285. [CrossRef]

2. Wang, Y.; Bian, J.; Zhao, Y.; Tang, J.; Jia, Z. Assessment of future climate change impacts on nonpoint source pollution in snowmelt period for a cold area using SWAT. Sci. Rep. 2018, 8, 2402. [CrossRef] [PubMed]

3. Ding, B.; Rezanezhad, F.; Gharedaghloo, B.; van Cappellen, P.; Passeport, E. Bioretention cells under cold climate conditions: Effects of freezing and thawing on water infiltration, soil structure, and nutrient removal. Sci. Total Environ. 2019, 649, 749-759. [CrossRef] [PubMed]

4. Xie, S.; Qu, J.; Lai, Y.; Zhou, Z.; Xu, X. Effects of freeze-thaw cycles on soil mechanical and physical properties in the Qinghai-Tibet Plateau. J. Mt. Sci. 2015, 12, 999-1009. [CrossRef]

5. Hayashi, M. The cold vadose zone: Hydrological and ecological significance of frozen-soil processes. Vadose Zone J. $2013,12$. [CrossRef]

6. Ireson, A.M.; Van Der Kamp, G.; Ferguson, G.; Nachshon, U.; Wheater, H.S. Hydrogeological processes in seasonally frozen northern latitudes: Understanding, gaps and challenges. Hydrogeol. J. 2012, 21, 53-66. [CrossRef]

7. Jiang, N.; Juan, Y.; Tian, L.; Chen, X.; Sun, W.; Chen, L. Modification of the composition of dissolved nitrogen forms, nitrogen transformation processes, and diversity of bacterial communities by freeze-thaw events in temperate soils. Pedobiologia 2018, 71, 41-49. [CrossRef]

8. Tian, H.; Wei, C.; Tan, L. Effect of freezing-thawing cycles on the microstructure of soils: A two-dimensional NMR relaxation analysis. Cold Reg. Sci. Technol. 2019, 158, 106-116. [CrossRef]

9. Wang, K.; Zhang, R.; Sheng, F. Characterizing heterogeneous processes of water flow and solute transport in soils using mul-tiple tracer experiments. Vadose Zone J. 2013, 12, 1-12. [CrossRef]

10. Gore, D.; Snape, I. Freeze-thaw cycling, moisture and leaching from a Controlled Release Nutrient source. Cold Reg. Sci. Technol. 2008, 52, 401-407. [CrossRef]

11. Harms, T.K.; Jones, J.B., Jr. Thaw depth determines reaction and transport of inorganic nitrogen in valley bottom permafrost soils: Nitrogen cycling in permafrost soils. Glob. Change Biol. 2012, 18, 2958-2968. [CrossRef] [PubMed]

12. Zhao, Q.; Chang, D.; Wang, K.; Huang, J. Patterns of nitrogen export from a seasonal freezing agricultural watershed during the thawing period. Sci. Total Environ. 2017, 599-600, 442-450. [CrossRef] [PubMed]

13. Zhao, P.; Tang, X.; Tang, J.; Zhu, B. The nitrogen loss flushing mechanism in sloping farmlands of shallow Entisol in south-western China: A study of the water source effect. Arab. J. Geosci. 2015, 8, 10325-10337. [CrossRef]

14. Campbell, J.L.; Reinmann, A.B.; Templer, P.H. Soil freezing effects on sources of nitrogen and carbon leached during snow-melt. Soil Sci. Soc. Am. J. 2014, 78, 297-308. [CrossRef]

15. Wu, M.; Wu, J.; Tan, X.; Huang, J.; Jansson, P.-E.; Zhang, W. Simulation of dynamical interactions between soil freez-ing/thawing and salinization for improving water management in cold/arid agricultural region. Geoderma 2019, 338, 325-342. [CrossRef]

16. Holten, R.; Bøe, F.; Almvik, M.; Katuwal, S.; Stenrød, M.; Larsbo, M.; Jarvis, N.; Eklo, O.M. The effect of freezing and thaw-ing on water flow and MCPA leaching in partially frozen soil. J. Contam. Hydrol. 2018, 219, 72-85. [CrossRef] [PubMed]

17. Debol'Skaya, E.I.; Gritsuk, I.I.; Debol'Skii, V.K.; Ionov, D.N.; Maslikova, O.Y. Effect of Bank Deformations on Pollutant Transport in Rivers in Cryolithozone: Laboratory and Mathematical Modeling. Water Resour. 2018, 45, 542-552. [CrossRef] 
18. Demand, D.; Selker, J.S.; Weiler, M. Influences of Macropores on Infiltration into Seasonally Frozen Soil. Vadose Zone J. 2019, 18, 1-14. [CrossRef]

19. Lundberg, A.; Ala-Aho, P.; Eklo, O.; Klöve, B.; Kværner, J.; Stumpp, C. Snow and frost: Implications for spatiotemporal infil-tration patterns-A review. Hydrol. Process. 2016, 30, 1230-1250. [CrossRef]

20. Mekonnen, B.A.; Mazurek, K.A.; Putz, G. Modeling of nutrient export and effects of management practices in a cold-climate prairie watershed: Assiniboine River watershed, Canada. Agric. Water Manag. 2017, 180, 235-251. [CrossRef]

21. Wang, K.; Wu, M.; Zhang, R. Water and Solute Fluxes in Soils Undergoing Freezing and Thawing. Soil Sci. 2016, 181, 193-201. [CrossRef]

22. Wang, K.; Wang, P.; Zhang, R.; Lin, Z. Characterizing the exudation of water and pollutants from soil into streams during soil-thawing period. J. Hydrol. 2020, 590, 125436. [CrossRef]

23. Song, Y.; Zou, Y.; Wang, G.; Yu, X. Altered soil carbon and nitrogen cycles due to the freeze-thaw effect: A meta-analysis. Soil Biol. Biochem. 2017, 109, 35-49. [CrossRef]

24. Iwata, Y.; Yazaki, T.; Suzuki, S.; Hirota, T. Water and nitrate movements in an agricultural field with different soil frost depths: Field experiments and numerical simulation. Ann. Glaciol. 2013, 54, 157-165. [CrossRef]

25. Zhou, Y.; Berruti, F.; Greenhalf, C.; Tian, X.; Henry, H.A. Increased retention of soil nitrogen over winter by biochar applica-tion: Implications of biochar pyrolysis temperature for plant nitrogen availability. Agric. Ecosyst. Environ. 2017, 236, 61-68. [CrossRef]

26. Kieta, K.A.; Owens, P.N.; Lobb, D.A.; Vanrobaeys, J.A.; Flaten, D.N. Phosphorus dynamics in vegetated buffer strips in cold climates: A review. Environ. Rev. 2018, 26, 255-272. [CrossRef]

27. Sambito, M.; Freni, G. Strategies for Improving Optimal Positioning of Quality Sensors in Urban Drainage Systems for NonConservative Contaminants. Water 2021, 13, 934. [CrossRef]

28. Yaroshenko, I.; Kirsanov, D.; Marjanovic, M.; Lieberzeit, P.A.; Korostynska, O.; Mason, A.; Frau, I.; Legin, A. Real-Time Water Quality Monitoring with Chemical Sensors. Sensors 2020, 20, 3432. [CrossRef]

29. Pan, X.; Tang, L.; Feng, J.; Liang, R.; Pu, X.; Li, R.; Li, K. Experimental Research on the Degradation Coefficient of Ammonia Nitrogen Under Different Hydrodynamic Conditions. Bull. Environ. Contam. Toxicol. 2020, 104, 288-292. [CrossRef]

30. Yu, Y.; Wu, J.; Wang, X.; Zhang, Z. Degradation of Inorganic Nitrogen in Beiyun River of Beijing, China. Procedia Environ. Sci. 2012, 13, 1069-1075. [CrossRef]

31. Huang, B.-S.; Hong, C.-h.; Du, H.-h.; Qiu, J.; Liang, X.; Tan, C.; Liu, D. Quantitative study of degradation coefficient of pollu-tant against the flow velocity. J. Hydrodyn. Ser. B 2017, 29, 118-123. [CrossRef]

32. Wen, Y.; Schoups, G.; Van De Giesen, N. Organic pollution of rivers: Combined threats of urbanization, livestock farming and global climate change. Sci. Rep. 2017, 7, srep43289. [CrossRef] [PubMed]

33. Wang, H.; He, P.; Shen, C.; Wu, Z. Effect of irrigation amount and fertilization on agriculture non-point source pollution in the paddy field. Environ. Sci. Pollut. R 2019, 26, 10363-10373. [CrossRef] [PubMed]

34. Woodward, S.J.; Stenger, R.; Bidwell, V.J. Dynamic analysis of stream flow and water chemistry to infer subsurface water and nitrate fluxes in a lowland dairying catchment. J. Hydrol. 2013, 505, 299-311. [CrossRef] 